Research letter

\title{
Individual variability of morphometric parameters feet of girls 18-19 years from Saratov region of the Russian Federation
}

\author{
Lyudmila V. Muzurova, Irina E. Kochelaevskaya \\ Saratov State Medical University n.a. V.I. Razumovsky, Saratov, Russia \\ Received 29 September 2016, Revised 10 January 2017, Accepted 24 January 2017
}

(C) 2017, Muzurova L.V., Kochelaevskaya I.E.

(C) 2017, Russian Open Medical Journal

\begin{abstract}
The individual variability of morphometric parameters of feet in 18-19 year-old girls (Saratov region, Russia) with different somatic types is examined.

Materials and Methods - 240 18-19 year-old girls (the students of Saratov State Medical University n.a. V.I. Razumovsky, the locals of Saratov region) were examined during the annual special medical examination. The somatic type's identification of the examined girls was conducted in accordance with B.A. Nikitiuk and A.I. Kozlov (1990). The examination of the foot type was performed with planthogram. During the research the shape of feet (Egyptian, Greek, Roman), the frequency of its occurrence in somatic types was determined. Shriter index, which characterizes the height of the arch of the foot and Veysflog index, which characterizes the spring function of the foot, was calculated. Also, the frequency of occurrence in the arches of the foot somatotype and its various forms were determined.

Results and Conclusion - The most common form of Egyptian foot is typical of women with mezomorphic hypotrophic and brachymorphic normotrophic somatotype; Roman foot - for brahimorphic hypertrophic and brahimorphic hypotrophic somatotypes; Greek foot - for dolihomorphic gipotorophic and brachymorphic hypertrophic somatotypes. High arch is common for Greek foot in the brahimorphic hypotrophic somatotype; elevated arch - for Roman foot in dolihomorphic normotrophic somatotype; flattened arch - for Egyptian foot in dolihomorphic normotrophic somatotype; platypodia - for Greek foot with brahimorphic hypotrophic somatotype. The foot of all forms and heights of the arch possesses a good spring function.
\end{abstract}

Keywords: somatotype, shape of feet, height of the arch, foot spring function.

Cite as Muzurova LV, Kochelaevskaya IE. Individual variability of morphometric parameters feet of girls 18-19 years from Saratov region of the Russian Federation. Russian Open Medical Journal 2017; 6: e0104.

Correspondence to Lyudmila V. Muzurova. Address: Human Anatomy Department, Saratov State Medical University n.a. V.I. Razumovsky, 112, B. Kazachya str., Saratov, 410012, Russia. Phone: +7(8452)669765. E-mail: Imuzurova@yandex.ru

\section{Introduction}

The examination of individual anatomical variability of musculoskeletal system structures has practical value for the solution of many problems of preventive medicine, orthopedics and traumatology $[1,2]$. In this respect, the foot, which is a finite and highly differentiated element, plays an important role. The foot is a spring unit for easy walking, determining its smooth, absorbing swing and body vibrations [3]. Standing daily constant physical activity of different duration and intensity, the foot reacts with the active resistance to preserve its anatomical integrity and biomechanical functionality $[4,5]$.

Slight structural changes of the foot, leading to its deformation, break complex kinematic chain implementing the agreed activities of the bones, joints and muscles. This can lead to the dystonia of the skeletal muscles, the appearance of pain, the appearance of calluses, corns, ulcers.

According to medical statistics, residents of the developed countries suffer from flat feet more often than the citizens of the developing countries. For example, in Europe and in America to $70 \%$ of people have some degree of flatfoot, and in India this defect occurs in only $4 \%$ of patients. In this aspect of the study of the morphology of the foot, cosidering its physical form and the individual type, acquires practical importance, as it is quite difficult to distinguish between all the options of foot norms and the initial stages of its deformation.

The purpose of this study is to examine individual variability of morphometric parameters feet of 18-19 year-old girls in Saratov region (Russia), with different somatic types.

\section{Material and Methods}

Body morphometry examination was performed on 240 women 18-19 years old who are the students of Saratov State Medical University n.a. V.I. Razumovsky (Saratov, Russia), and who are indigenous inhabitants of Saratov region of the Russian Federation. Measurements were conducted during thorough annual medical examination of students in the university polyclinic in compliance with the principles of voluntary participation, individual rights and freedoms guaranteed by Article 21 of the Constitution of the Russian Federation. 


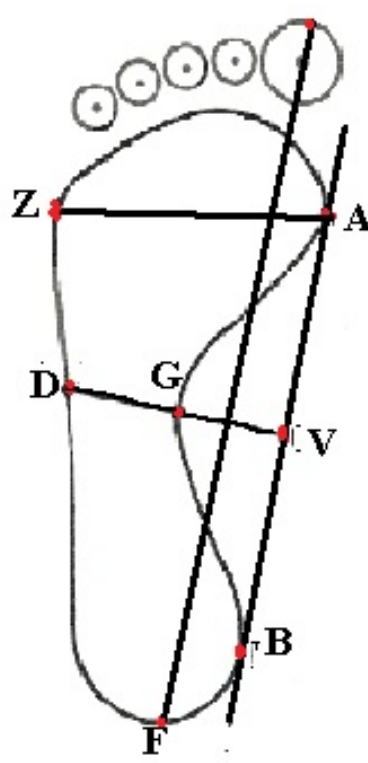

Figure 1. Plantogram (sheme)

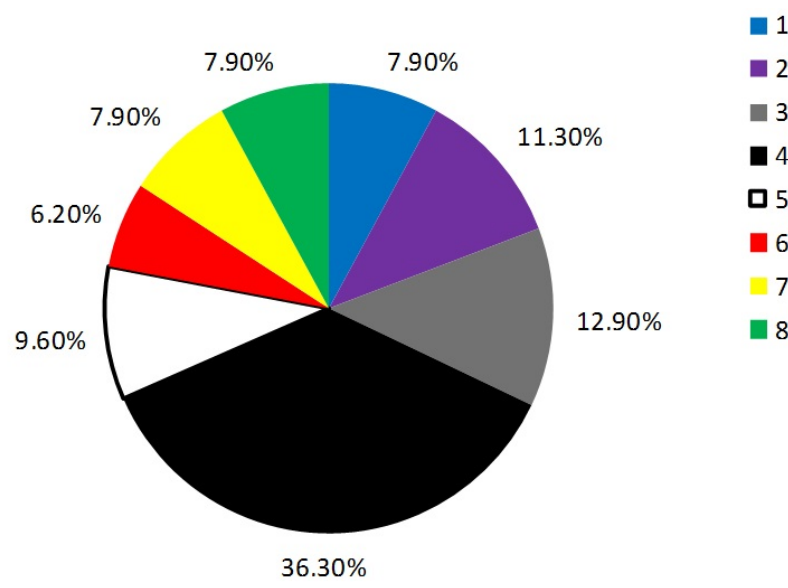

Figure 2. The frequency (\%) of somatic types in the studied group: 1 - dolihomorphic hypotrophic; 2 - dolihomorphic normotrophic; 3 - mezomorphic hypotrophic; 4 - mezomorphic normotrophic; 5 - mezomorphic hypertrophic; 6 - brachymorphic hypotrophic; 7-brachymorphic normotrophic; 8-brachymorphic hypertrophic.

The examination of young women somatic types was conducted in accordance with the research made by B.A. Nikitiuk and A.I. Kozlov (1990) [6], who had determined nine somatic types such as: dolihomorphic hypotrophic, dolihomorphic normotrophic, dolihomorphic hypertrophic, mezomorphic hypotrophic, mezomorphic normotrophic, mezomorphic hypertrophic, brahimorphic hypotrophic, brahimorphic normotrophic, brahimorphic hypertrophic.

Foot morphometry was performed with planthogram. The processing was done by drawing the scheme.

By the length of the fingers there were determined three types of feet:

1) Egyptian type of foot (Egyptian foot) - the first finger is followed by the second, the third, the fourth and the little finger in descending order;
2) Roman type or rectangular type of foot (Roman foot) - all fingers are of approximately equal length;

3) Greek type of foot (Greek foot) - the second finger is longer than the first and the third fingers.

Shriter index, which characterizes the height of the arch of the foot, was calculated. On the Plantogram the tangent line $(A B)$ is drawn to the most salient points of the inside of print $A$, from the middle of which the perpendicular to the intersection with the outer edge (VD) print and perpendicular between the outer and inner edges of the print (GD) are erected (Figure 1).

The shape of the foot is determined by the index:

$$
I=(G D * 100) / V D,
$$

I - Shriter index; GD - cup perpendicular (in cm); VD - part of the perpendicular (in $\mathrm{cm}$ ) [7].

According to the meaning of the Shriter index, all feet were divided into the following groups:

1) high arch foot - with index meaning of up to $36 \%$;

2) high vault foot - with index meaning of up to $43 \%$;

3) normal arch foot - with index meaning of up to $50 \%$;

4) flattened arch foot- with index meaning of up to $60 \%$;

5) platypodia - with index meaning from $60 \%$ to $70 \%$.

Weisflog index representing the ratio of the length of the foot to its width was calculated. The length of the foot was determined on the plantogram from the point $F$ to the end of the longest toe; the width of the foot - on the I-V level of metatarsus-phalangeal joints (AZ line). In the most common cases, $W$ index is between 2 and 3. The meaning approaching "2" indicates the transverse platypodia, whereas the meaning nearing " 3 " shows an ideal foot cross-linking and is a good indicator of its spring function.

The obtained data was processed by statistical analysis. The differences between frequencies were considered reliable at $95 \%$ $(\mathrm{P}<0.05)$ probability threshold (based on $\mathrm{t}$-test). The variation of anthropometric parameters was evaluated by coefficient of variation (CV). The variation was considered weak if $\mathrm{CV}$ does not exceed $10 \%$, the average - when CV was $11.0-25.0 \%$, and significant if $\mathrm{CV}>25.0 \%$. When was $\mathrm{CV}>50.0 \%$ the distribution was considered asymmetric. All combination options were preprocessed for "pop-up option" [8].

\section{Results}

The somatic type's identification of 18-19 years-old girls showed that the examined group includes all somatic types revealed in according with the method of B.A. Nikitiuk and A.I. Kozlov (1990) except dolihomorphic hypertrophic somatic type. More often girls have mezomorphic normotrophic somatic type (36.3\%). In minor cases were defined the mezomorphic hypotrophic type, dolihomorphic normotrophic and mezomorphic hypertrophic somatic types. Dolihomorphic hypotrophic, brachymorphic normotrophic, brachymorphic hypertrophic somatic types are defined 4.5 times rarely and with the same frequency (7.9\%). Brachymorphic hypotrophic somatic type is determined in the rarest cases (6.2\%) among the examined group (Figure 2). 


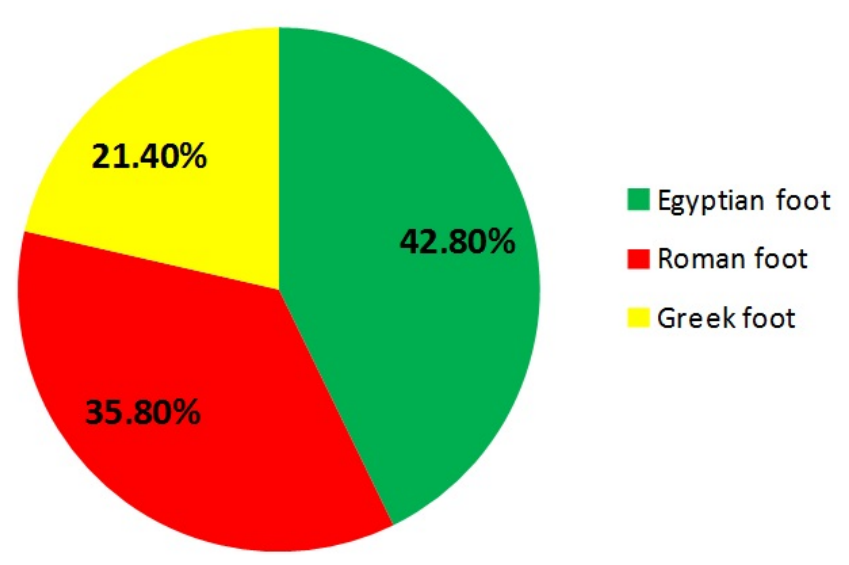

Figure 3. The frequency (\%) of morphological types of feet in 18-19 yearsold girls.

Table 1. The frequency of foot morphological cases among women of different somatic types

\begin{tabular}{lcccccc}
\multicolumn{1}{c}{ Somatic type } & \multicolumn{1}{c}{ Egyptian } & \multicolumn{3}{c}{ Roman } & \multicolumn{2}{c}{ Greek } \\
& no. & $\%$ & no. & $\%$ & no. & $\%$ \\
\hline Dolih. hypotrophic & 6 & 31.59 & 7 & 36.84 & 6 & 31.59 \\
Dolih. normotrophic & 12 & 44.44 & 10 & 37.04 & 5 & 18.52 \\
Mez. hypotrophic & 18 & 58.06 & 11 & 35.48 & 2 & 6.45 \\
Mez. normotrophic & 30 & 35.29 & 31 & 36.47 & 24 & 28.24 \\
Mez. hypertrophic & 12 & 52.17 & 7 & 30.43 & 4 & 17.39 \\
Brah. hypotrophic & 6 & 40.00 & 6 & 40.00 & 3 & 20.00 \\
Brah. normotrophic & 11 & 57.89 & 6 & 31.58 & 2 & 10.53 \\
Brah. hypertrophic & 5 & 26.36 & 8 & 42.11 & 6 & 31.58
\end{tabular}

Dolih., Dolihomorphic; Mez., Mezomorphic; Brah., Brahimorphic.

Table 2. Shriter Index of women in the joint group considering the somatic type

\begin{tabular}{lccccc}
\hline Somatic type & $\mathrm{R} / \mathrm{L}$ & & $\mathrm{c}$ Variational statistics & \\
& & $\mathrm{Min}-\mathrm{Max}$ & $\mathrm{M} \pm \mathrm{m}$ & $\mathrm{SD}$ & $\mathrm{CV}, \%$ \\
\hline Joint group & $\mathrm{R}$ & $20.50-91.80$ & $48.16 \pm 0.87$ & 13.19 & 27.39 \\
& $\mathrm{~L}$ & $15.60-95.00$ & $48.54 \pm 0.88$ & 13.36 & 27.52 \\
Dolih. hypot. & $\mathrm{R}$ & $27.90-88.70$ & $49.64 \pm 3.75$ & 16.33 & 32.90 \\
& $\mathrm{~L}$ & $33.30-84.80$ & $54.22 \pm 3.88$ & 16.90 & 31.16 \\
Dolih. norm. & $\mathrm{R}$ & $27.00-90.60$ & $46.86 \pm 2.13$ & 11.07 & 23.62 \\
& $\mathrm{~L}$ & $25.90-94.80$ & $48.66 \pm 2.29$ & 11.90 & 24.46 \\
Mez. hypot. & $\mathrm{R}$ & $29.10-91.10$ & $47.39 \pm 2.57$ & 14.32 & 30.22 \\
& $\mathrm{~L}$ & $31.10-91.56$ & $46.25 \pm 2.35$ & 13.07 & 28.26 \\
Mez. norm. & $\mathrm{R}$ & $22.50-91.80$ & $47.59 \pm 1.26$ & 11.63 & 24.44 \\
& $\mathrm{~L}$ & $15.60-95.00$ & $47.46 \pm 1.48$ & 13.60 & 28.67 \\
Mez. hyper. & $\mathrm{R}$ & $20.50-88.70$ & $51.07 \pm 3.27$ & 15.69 & 30.72 \\
& $\mathrm{~L}$ & $32.60-84.80$ & $49.35 \pm 2.60$ & 25.23 & 2.60 \\
Brah. hypot. & $\mathrm{R}$ & $28.98-78.40$ & $45.11 \pm 9.01$ & 20.15 & 44.67 \\
& $\mathrm{~L}$ & $35.10-75.90$ & $47.02 \pm 7.28$ & 16.27 & 34.61 \\
Brah. norm. & $\mathrm{R}$ & $30.00-57.70$ & $44.16 \pm 1.72$ & 7.50 & 16.99 \\
& $\mathrm{~L}$ & $33.76-74.69$ & $46.79 \pm 2.11$ & 9.19 & 19.64 \\
Brah. hyper. & $\mathrm{R}$ & $28.98-87.70$ & $55.20 \pm 3.81$ & 16.61 & 31.23 \\
& $\mathrm{~L}$ & $38.80-84.80$ & $53.46 \pm 3.49$ & 14.81 & 27.70 \\
\hline
\end{tabular}

$\mathrm{R}$, right; $\mathrm{L}$, left; Min, minimum; Max, maximum; $\mathrm{M} \pm \mathrm{m}$, mean with its standard error; SD, standard deviation; CV, coefficient of variation; Dolih., Dolihomorphic; Mez., Mezomorphic; Brah., Brahimorphic; hypot., hypotrophic; norm., normotrophic; hyper., hypertrophic.
The following frequency of foot morphological types in 18-19 years-old women without considering somatic type is: the most common is Egyptian foot (42.8\%); less common is Roman foot (7.0\% less); the rarest is Greek foot ( 2 times less than Egyptian) (Figure 3).

The girls with dolihomorphic hypotrophic somatic type, the mentioned foot types occur with almost equal frequency (31.59$36.84 \%)$. In dolihomorphic normotrophic group most of the girls have Egyptian type of foot (44.44\%); less common is Roman $(7.4 \%$ less); the rarest is Greek (2.4 times less than Egyptian foot). In mezomorphic hypotrophic group the Egyptian foot is determined the most frequently (58.06\%); Roman - 1.6 times less; Greek - the rarest (6.45\%). In mezomorphic normotrophic group Egyptian and Roman feet occur with the same frequency $(25.29 \%$ and $36.47 \%$ respectively); Greek foot is determined rarely ( $8 \%$ less). In mezomorphic hypertrophic group the Egyptian foot is often determined (52.17\%); Roman and Greek feet - are less by 1.7 and 3.1 times respectively. In brahimorphic hypotrophic group Egyptian and Roman feet are presented in majority of cases with the same frequency $(40.00 \%)$; Greek foot is determined in the group 2 times less. In brahimorphic normotrophic group Egyptian foot is determined in most cases; Roman and Greek - 1.8 and 5.7 times less. In brahimorphic hypertrophic group the girls regularly have Roman foot (42.11\%); less more rare Greek and Egyptian - by $10.52 \%$, and 1.6 times respectively (Table 1 ).

In the majority of cases the type of right foot concurs with the type of the left foot.

Analysis of Shriter index has shown that the joint group as well as the group of girls who are brachymorphic hypotrophic, brachymorphic normotrophic, dolihomorphic normotrophic, mezomorphic hypotrophic, mezomorphic normotrophic somatic types have a normal foot arch height, both right and left. The girls of dolihomorphic normotrophic somatic type have the right foot with normal height of the arch, the left one is determined with a flattened arch $(P<0.05)$; the girls mesomorphs hypertrophy - on the right the arch is flattened on the left - normal. The girls with brachymorphic hypertrophic somatic type have flattened arches of the foot, both right and left (Table 2).

In the joint group of girls 18-19 years old and among all somatic types Weisflog index tends to the meaning "3", which indicates the normal foot spring function.

The analysis of the arch height frequency has shown the Greek type has the normal height more ofen (34.69\%). In Roman and Egyptian feet the normal height arch is determined more rarel (1.79\% and $7.14 \%)$. Flattened arch is common for Egyptian foot (27.55\%). In Roman and Greek feet the flattened arch is determined by $7 \%$ less and with the same frequency. Platypodia is most common for girls with a Greek foot (12.24\%). The Egyptian and Roman feet have less platypodia cases for $3.00 \%$ and with the same frequency. Raised arch is more common for Egyptian and Roman feet (27.55\% and 28.05\%). The girls with a Greek foot the raised arch is determined almost 2 times rarer. High arch is common for Greek foot (18.37\%). In girls with the Egyptian and Roman feet, the high arch is defined 2.3 times rarer (Table 3 ).

Among the girls 18-19 years old without considering somatotype the normal arch height is more common on the right side than on the left (by 5.2\%). Flattened arch is found more often on the left side than on the right (at $6.11 \%, \mathrm{P}<0.05 \%$ ). Raised arch, high arch and platypodia are determined on the right and left sides with almost the same frequency (Table 4). 
Table 3. The frequency of foot arches considering the foot types

\begin{tabular}{|c|c|c|c|c|c|c|c|c|c|c|}
\hline \multirow[t]{3}{*}{ Foot type } & \multicolumn{10}{|c|}{ Foot arch } \\
\hline & \multicolumn{2}{|c|}{ High arch } & \multicolumn{2}{|c|}{ Raised arch } & \multicolumn{2}{|c|}{ Normal arch } & \multicolumn{2}{|c|}{ Flattened arch } & \multicolumn{2}{|c|}{ Platypodia } \\
\hline & no. & $\%$ & no. & $\%$ & no. & $\%$ & no. & $\%$ & no. & $\%$ \\
\hline Egyptian & 8 & 8.16 & 27 & 27.55 & 27 & 27.55 & 27 & 27.55 & 9 & 9.18 \\
\hline Roman & 7 & 8.54 & 23 & 28.05 & 27 & 32.93 & 17 & 20.73 & 8 & 9.77 \\
\hline Greek & 9 & 18.37 & 7 & 14.29 & 17 & 34.69 & 10 & 20.41 & 6 & 12.24 \\
\hline
\end{tabular}

Table 4. The frequency of foot arches in various somatic types

\begin{tabular}{|c|c|c|c|c|c|c|c|c|c|c|c|}
\hline \multirow[t]{3}{*}{ Somatic type } & \multirow[t]{3}{*}{ Right/Left } & \multicolumn{10}{|c|}{ Foot arch } \\
\hline & & \multicolumn{2}{|c|}{ High arch } & \multicolumn{2}{|c|}{ Raised arch } & \multicolumn{2}{|c|}{ Normal arch } & \multicolumn{2}{|c|}{ Flattened arch } & \multicolumn{2}{|c|}{ Platypodia } \\
\hline & & no. & $\%$ & no. & $\%$ & no. & $\%$ & no. & $\%$ & no. & $\%$ \\
\hline \multirow[t]{2}{*}{ Dolihomorphic hypotrophic } & Right & 4 & 21.05 & 2 & 10.53 & 7 & 36.84 & 2 & 10.53 & 4 & 21.05 \\
\hline & Left & 3 & 15.79 & 1 & 5.26 & 5 & 26.36 & 4 & 21.05 & 6 & 31.58 \\
\hline \multirow[t]{2}{*}{ Dolihomorphic normotrophic } & Right & 1 & 3.70 & 10 & 37.04 & 9 & 33.33 & 5 & 18.52 & 2 & 7.41 \\
\hline & Left & 1 & 3.70 & 9 & 33.33 & 5 & 18.52 & 10 & 37.04 & 2 & 7.41 \\
\hline \multirow[t]{2}{*}{ Mezomorphic hypotrophic } & Right & 5 & 16.13 & 10 & 32.26 & 9 & 29.03 & 1 & 3.23 & 6 & 19.35 \\
\hline & Left & 5 & 16.13 & 9 & 29.03 & 8 & 25.81 & 6 & 19.35 & 3 & 9.68 \\
\hline \multirow[t]{2}{*}{ Mezomorphic normotrophic } & Right & 10 & 11.76 & 21 & 24.71 & 30 & 35.29 & 15 & 17.65 & 9 & 10.59 \\
\hline & Left & 9 & 10.59 & 22 & 25.88 & 29 & 34.12 & 15 & 17.65 & 10 & 11.76 \\
\hline \multirow[t]{2}{*}{ Mezomorphic hypertrophic } & Right & 2 & 8.70 & 4 & 17.39 & 9 & 39.13 & 4 & 17.39 & 4 & 17.39 \\
\hline & Left & 2 & 8.70 & 2 & 8.70 & 8 & 34.78 & 7 & 30.43 & 2 & 8.70 \\
\hline \multirow[t]{2}{*}{ Brahimorphic hypotrophic } & Right & 6 & 40.00 & 3 & 20.00 & 3 & 20.00 & 3 & 20.00 & 0 & 0 \\
\hline & Left & 3 & 20.00 & 6 & 40.00 & 3 & 20.00 & 0 & 0 & 3 & 20.00 \\
\hline \multirow[t]{2}{*}{ Brahimorphic normotrophic } & Right & 3 & 15.79 & 3 & 15.79 & 10 & 52.63 & 3 & 15.79 & 0 & 0 \\
\hline & Left & 2 & 10.53 & 4 & 21.05 & 8 & 42.11 & 4 & 21.05 & 1 & 5.26 \\
\hline \multirow[t]{2}{*}{ Brahimorphic hypertrophic } & Right & 2 & 10.53 & 4 & 21.05 & 3 & 15.79 & 6 & 31.58 & 4 & 21.05 \\
\hline & Left & 2 & 10.53 & 1 & 5.26 & 8 & 42.11 & 4 & 21.05 & 4 & 21.05 \\
\hline \multirow[t]{2}{*}{ Joint group } & Right & 29 & 12.66 & 55 & 24.02 & 78 & 34.06 & 37 & 16.16 & 30 & 13.10 \\
\hline & Left & 25 & 10.92 & 57 & 24.89 & 67 & 29.26 & 51 & 22.27 & 29 & 12.66 \\
\hline
\end{tabular}

The analysis of the foot arches frequency occurrence has shown that the girls of dolihomorphic hypotrophic somatotype mostly have a normal foot arch height. The normal height is determined on the right side more often than on the left in $10.48 \%$. This difference is statistically significant $(P<0.05)$. Raised arch and high arch are determined more often on the right side than on the left (in 2-fold $(P<0.05)$ and $5.26 \%(P>0.05)$. Flattened arch and platypodia are common for the left side (in 2-fold and $10.5 \%$, respectively $(P<0.05)$.

Mezomorphic hypotrophic group frequently has raised arches on both sides: on the right (32.26\%) and on the left (29.03\%). Normal arch height is determined rarely - on the right side is up to $29.03 \%$ and $25.81 \%$ on the left one. High arch is determined with the same frequency both on the right and left sides (16.13\%). Flattened foot arch is more common on the left side than on the right one $(6.3 \%)(P<0.05)$. Platypodia is more likely to be observed on the right side than on the left $(2$ times) $(P<0.05)$ for this somatotype of women.

In mezomorphic normotrophic group the most widely-spread height of foot arch is normal arch, both on the right and on the left sides $(30.0 \%$ and $29.0 \%$ respectively). Fewer cases are presented by high arch $(21.0 \%$ on the right side and $22.0 \%$ on the left) and by flattened arch (17.65\% both on the right and left sides). The rarest cases in this somatotype group are presented by high arch $(11.76 \%$ on the right side and $10.59 \%$ on the left) and platypodia ( $10.59 \%$ on the right and $11.76 \%$ on the left).

In mezomorphic hypertrophic group in most cases girls have a normal arch height: on the right side normal arch is presented more often than on the left (5.5\%) $(P>0.05)$. Flattened arch is more frequently defined on the left side than on the right (1.8-fold;
$\mathrm{P}<0.05)$; platypodia - on the right side $(2.2$-fold; $\mathrm{P}<0.05)$. Raised arch in this group is more common for the right side than for the left $(2.2$-fold; $\mathrm{P}<0.05)$. High arch women in this group are quite rare (8.7\% both right and left sides).

The girls with brahimorphic hypotrophic somatotype have normal arch in $20.0 \%$ of cases, both on the right and left sides. Flattened arch is determined only on the right side $(20.0 \%)$; platypodia - only on the left side (20.0\%). Raised arch on the left side is found 2 times more often than on the right side; high arch is more often on the right side than on the left ( 2 times).

In the group of brahimorphic normotrophic women in the majority of cases have the normal arch height on the right side it is $10.5 \%$ more often than on the left $(P<0.05)$. Flattened arch is more frequently defined on the left side than on the right $(5.2 \%$, $\mathrm{P}>0.05$ ). Platypodia is detected in single observation only on the left side (5.2\%). Raised arch is most common on the left side $(5.2 \%$; $\mathrm{P}>0.05)$; high arch is most common on the right side $(5.26 \%$; $P>0.05$ ).

For brahimorphic hypertrophic girls the normal height arch is typical on the left side and is revealed in $42.11 \%$ of cases. On the right side the normal height of the arch is defined 2.8 times rarer $(P<0.05 \%)$. Flattened arch in the group is determined quite often on the right side in $31.58 \%$ of cases, and on the left - by $10.5 \%$ rarer $(P<0.05 \%)$. The girls with this somatotype have raised arch of the right side 4 times more often than on the left. Platypodia and high arches are defined with the same frequency both on the right and on the left sides ( $21.05 \%$ and $10.53 \%$ respectively).

Combined volatility of Weisflog index with height of foot arches has shown that in all groups the index approaches the 
meaning "3", which is an indicator of good spring function of foot despite the identified changes in the height of the arches

\section{Discussion}

The functional diagnostics is one of the leading trends in the health system. It is aimed not only at making exact diagnosis and evaluating undertaken therapeutic treatment, but also at the timely detection of individual variability combinations, which can initiate the forthcoming pathology. The timely detection of predisposition to the feet anatomical changes among the girls of different somatic types considering their feet shapes and early preventive measures will reduce the risk of the beginings of spine diseases, of the formation of irregular pelvic shape and, as a consequence, of the viscera dislocation.

Available data from specific literature indicates a high occurrence of the various changes in the height of the foot arch. According to various authors, the normal height of the foot arch is typical only for $13-25 \%$ of girls [9-11]. However, there are no presented data about the changes in the foot arch of its various forms taking in to considiration the somatic type of human.

Our research evidences a high frequency of the normal foot arch cases (up to 35\%). What is more the obtained data considers not only the shape of foot, but also the somatic type of the examined girls.

\section{Conclusion}

Egyptian form of the foot is typical for women with mezomorphic hypotrophic and brachymorphic normotrophic somatotype. Roman foot is common for girls with brahimorphic hypertrophic and brahimorphic hypotrophic somatotypes. Greek foot is widely-spread among dolihomorphic hypotrophic and brahimorphic hypertrophic women.

High foot arch is usually presented by Greek foot among brahimorphic hypotrophic somatotype; raised arch - by Roman foot among dolihomorphic normotrophic somatotype; flattened arch - by Egyptian foot among dolihomorphic normotrophic somatotype; platypodia - by Greek foot among brahimorphic hypotrophic somatotype.

All forms of feet and its arch height variability indicate its good foot spring function, testifying to the normal physical load distribution.

\section{Conflict of interest: none declared.}

\section{References}

1. Perepelkin Al, Krayushkin Al, Atroshchenko ES. Somatotypological specifications of foot in boys and girls from Russia and Malaysia. Journal of Anatomy and Histopathology 2015; 4(3): 97. Russian

2. Perepelkin A, Mandrikov V, Krayuschkin A, Atroschenko Y. Our method the determination of the mechanical features of the human foot. Bulletin of Science and Practice 2016; (4): 154-160. Russian http://dx.doi.org/10.5281/zenodo.54025.

3. Konnova OV, Aleshkina OYu, Nikolenko VN, Galaktionova NA, Bondareva EV, Lukina GA. Combined variation of linear parameters of foot with different forms of lower limb. Bulletin of Medical Internet Conferences 2015; 5(7): 1073. Russian

4. Schwend RM, Drennan JC. Cavus foot deformity in children. J Am Acad
Orthop
Surg 2003;
11(3):
201-211.

5. Kitaoka HB, Patzer GL. Subtalar arthrodesis for posterior tibial tendon dysfunction and pes planus. Clin Orthop Relat Res 1997; (345): 187 194. https://www.ncbi.nlm.nih.gov/pubmed/9418639.

6. Nikityuk BA. Human morphology. Moscow, Russia: MGU, 1990; 343 p. Russian

7. Tsarapkin LV. Physiological aspects of rehabilitation of disorders of the musculoskeletal system in childhood and adolescence: PhD thesis. Volgograd, Russia, 2010; 27 p. Russian

8. Plokhinskiy NA. Biometrics. Moscow, Russia: MGU, 1970; 367 p. Russian

9. Konnova OV, Nikolenko VN, Syrova OV. Correlation relationship between foot dimensional characteristics and anthropometric indices in 17-19 years-old girls. Advances in Current Natural Sciences 2009; (5): 122-123. Russian

10. Takhmezov RT, Aleksina LA. Structure of the foot in the European race girls belonging to different ethnic groups. The Scientific Notes of the 1 . P. Pavlov St. Petersburg State Medical University 2012; XIX(3): 86-87. Russian

11. Perepyolkin Al, Mandrikov VB, Krayuschkin Al, Troschenko ES. Computer plantographic analysis of anatomical parameters of foot in the Malaysian and Russian girls. Journal of New Medical Technologies 2013; 20(2): 143-146. Russian

Authors:

Lyudmila V. Muzurova - MD, D.Sc., Professor, Human Anatomy Department, Saratov State Medical University n.a. V.I. Razumovsky, Saratov, Russia. http://orcid.org/0000-0001-7839-2399.

Irina E. Kochelaevskaya - MD, Graduate Student, Human Anatomy Department, Saratov State Medical University n.a. V.I. Razumovsky, Saratov, Russia. http://orcid.org/0000-0002-5525-4089. 